\title{
Healthy selfing: Theoretically optimal environments for the development of tacting and deictic relational responding
}

Desenvolvendo um Self saudável: Ambientes teoricamente otimizados para o desenvolvimento de respostas de tato e de respostas relacionais dêiticas Desarrollo de un yo saludable: entornos optimizados teóricamente para el desarrollo de tactos como respuestas y respuestas relacionales deícticas

\author{
Alison Stapleton', Louise McHugh'
}

[1] School of Psychology, University College Dublin, Belfield, Dublin 4, Ireland) I Título abreviado: Tacting and deictic relations I Email: Louise McHugh - louise. mchugh@ucd.ie I doi: 10.18761/PAC.2021.v12.RFT.10

\begin{abstract}
From a relational frame theory perspective, our sense of self is a by-product of language that arises from transformation of stimulus functions through relational framing of our own responding. In this way, selfing is an important action that allows us to clarify our needs, wants, and what matters to us. Tacting and deictic relational responding are two processes that are instrumental to the development of a healthy selfing repertoire. This paper provides an overview of tacting and deictic relational responding in accordance with relational frame theory in addition to features of an optimal environment for shaping these processes. In terms of tacting, it is important to consider learning environment sensitivity, consequence availability, the individual's experience, and to facilitate rich discussions of private events. In terms of deictic relational responding, it is important to provide frequent interactions that contain multiple exemplars of distinctions between self and others in addition to rich discussions of private events while also tailoring to the individual when drawing from training protocols. We conclude with a brief overview of the current evidence base regarding the identified features.
\end{abstract}

Keywords: tacting; selfing; deictic relational responding; private events; relational frame theory; perspective-taking; pliance 
Resumo: Da perspectiva da teoria das molduras relacionais (RFT), nosso senso de eu é um subproduto da linguagem que surge da transformação de função de estímulos por meio de emolduramentos relacionais do nosso próprio responder. Nesse sentido, o Eu como comportamento (selfing) é uma ação importante que nos permite clarificar nossas necessidades, desejos e o que importa para nós. Respostas de tato e respostas relacionais dêiticas são dois processos instrumentais para o desenvolvimento de um repertório saudável relacionado ao Self. Esse artigo apresenta uma visão geral sobre respostas de tato e respostas relacionais dêiticas de acordo com a RFT e também características de um ambiente otimizado para a modelagem desses processos. Em termos de tato, é importante considerar o aprendizado da sensibilidade ao ambiente, disponibilidade de consequências, a experiência do indivíduo e a facilitação de discussões ricas sobre eventos privados. Em termos de responder relacional dêitico, é importante prover interações frequentes que contêm múltiplos exemplares de distinção entre o eu e os outros, além de discussões ricas sobre eventos privados adaptando os protocolos às necessidades individuais. Nós concluímos com uma breve visão geral das evidências que suportam as características ambientais identificadas.

Palavras-chave: tato, selfing, responder relacional dêitico, eventos privados, teoria das molduras relacionais, tomada de perspectiva, aquiescência.

Resumen: Desde la perspectiva de la teoría de los marcos relacionales, nuestro sentido del yo es un subproducto del lenguaje que surge de la transformación de las funciones de estímulo a través del encuadre relacional de nuestro propio responder. De esta manera, el Yo como comportamiento (selfing) es una acción importante que nos permite aclarar nuestras necesidades, deseos y lo que nos importa. El tactar y la respuesta relacional deíctica son dos procesos que son fundamentales para el desarrollo de un repertorio saludable relacionado con el Yo como comportamiento. Este artículo proporciona una descripción general de la respuesta relacional deíctica y tactante de acuerdo con la teoría de los marcos relacionales, además de las características de un entorno óptimo para dar forma a estos procesos. En términos de tacto, es importante considerar la sensibilidad del entorno de aprendizaje, la disponibilidad de consecuencias, la experiencia del individuo y facilitar discusiones enriquecedoras de eventos privados. En términos de respuesta relacional deíctica, es importante proporcionar interacciones frecuentes que contengan múltiples ejemplos de distinciones entre el uno mismo y los demás, además de discusiones enriquecedoras de eventos privados, mientras que también se adapta al individuo cuando se basa en protocolos de entrenamiento. Concluimos con una breve descripción de la base de evidencia actual con respecto a las características identificadas.

Palabras clave: tacto, autorrealización, respuesta relacional deíctica, eventos privados, teoría de los marcos relacionales, toma de perspectiva, aquiescencia. 
Learned through interactions with the verbal community, a sense of self is fundamentally instrumental in terms of our ability to understand ourselves, our environment, and each other. Our sense of self enables us to identify and communicate our needs, wants, and values, further contributing to how we navigate the world and, in particular, our social environment, allowing us to live a meaningful and fulfilling life (McHugh et al., 2019).

From a relational frame theory (RFT) perspective, our sense of self is a by-product of language, arising from transformation of stimulus functions through relational framing of our own responding (Hayes et al., 2001). Therefore, from an RFT perspective, it is more appropriate to use 'selfing' as an action than 'self' as a noun. We learn to self just like we learn any other activity, such as riding a bike. Specifically, we learn to self through responding to questions about our self. For example, "What were you doing there?", "What are you holding now?", "When will your Ph.D. be completed?". Through responding to these questions, a stable sense of self emerges to the point where we no longer need to be asked the questions for us to be engaging in selfing.

Through a developmental lens, this paper describes two processes, namely tacting and deictic relational responding, that are fundamental to a healthy selfing repertoire. We will begin each section by providing a brief description of the process followed by an overview of its importance. Throughout this paper, we will present illustrative examples to demonstrate how a particular learning history may lead to a particular outcome with regard to tacting and deictic relational responding. Please note that the presented examples reflect one of many possibilities and should not be viewed as deterministic or through a "cause-and-effect" lens. Rather, our intention with these examples is to facilitate discussion and highlight why a particular component may be worthy of consideration. We will then present features of an optimal environment for shaping the relevant repertoire and will conclude each section with an overview of the evidence base.

\section{Tacting}

Skinner (1957) defined tacting as verbal behavior controlled by stimuli from the "world of things and events which a speaker is said to 'talk about"' (p.81). From an RFT perspective, tacting is not necessarily verbal (i.e., RFT differentiates between verbal and non-verbal tacts). In accordance with RFT, a verbal tact is one that does not require a direct history of reinforcement for the tact relation to emerge (i.e., relations are derived between stimuli via their participation in relational networks). True verbal tacts of this kind are likely rare (i.e., most tacts have been previously reinforced in some way). However, Barnes-Holmes et al. (2000) argue that it is useful to define tacts that have been explicitly reinforced as verbal tacts when the stimulus being tacted participates in relational networks with other stimuli. This verbal-non-verbal distinction enhances our understanding of tacting as a process, allowing us to view verbal tacts as involving the construction of contextually controlled networks of relations between stimuli, therefore enabling us to better predict behavioral patterns that are not readily explained by histories of direct reinforcement (see BarnesHolmes et al., 2000 for a complete discussion).

Initially, tacting is learned via specific social reinforcement. For example, consider a child that is reinforced for saying "dada" when their father enters the room. The same reinforcers would not be contacted if the child had said "mama". Subsequently, the verbal community reinforces tacting by indicating that they understand the speaker. Simply put, tacts are later governed by general non-specific social consequences (i.e., generalized reinforcers) that indicate that the listener has been understood, such as attention, nodding, or sympathy for example (Pierce \& Levin, 2019).

Teaching a child to accurately tact their internal experiences is complex. Unlike physically present stimuli, a parent cannot literally see what experience the child is trying to name (Darrow \& Follette, 2014a). However, learning to discriminate and label private events is crucial for the development of flexible responding that is sensitive to shifting environmental contingencies. Contacting our current experiences is easier when we have labels to describe 
them. Noticing our private events as they occur allows us to better predict how particular contexts will impact us and therefore provides us with space to optimize our behavior (McHugh et al., 2019). For example, consider a child noticing that they are less cranky after they have had their daily nap. Being aware of their level of crankiness may help the child to notice that naps beneficially impact their disposition. In a similar vein, Conallen and Reed (2017) found that children with Autism Spectrum Disorder were better able to initiate conversations about their experiences after they had been provided with language that could be used to describe private events. Though complex, via external corre- lates (i.e., public accompaniments), the verbal community can endeavor to shape repertoires for accurately tacting private events (McHugh et al., 2019). In addition, caregivers can strive to provide children with an environment that sets the context for tacting of internal experiences. Drawing on Darrow and Follette (2014a) and McHugh et al. (2019), we will now describe some features of a theoretically optimal environment for the development of accurate repertoires for tacting private events. See Table 1 for a summary of these features. See Darrow and Follette (2014b) and Kanter et al. (2014) for a discourse on Darrow and Follette (2014a).

\section{Table 1. A summary of the features of a theoretically optimal environment for the development of accurate repertoires for tacting private events.}

\begin{tabular}{ll}
\hline Feature & Summary \\
\hline Appropriate sensitivity & $\begin{array}{l}\text { The learning environment is sensitive enough to capitalize on opportuni- } \\
\text { ties for shaping tacting without rendering explicit tacts of private events } \\
\text { redundant. }\end{array}$ \\
Appropriate consequences are delivered & $\begin{array}{l}\text { The learning environment provides reinforcement for tacting private events, } \\
\text { ensuring those repertoires do not undergo extinction. The learning environ- } \\
\text { ment enables a child to safely explore their internal experiences, allowing } \\
\text { them to better connect with their private events. }\end{array}$ \\
Prioritizes the individual's experience & $\begin{array}{l}\text { The learning environment contextualizes pliance, sensitizes a child to their } \\
\text { own experience, and does not attempt to deliberately distort private events. } \\
\text { The learning environment facilitates rich discussion of private events, equip- } \\
\text { pang a child to effectively tact and communicate across contexts. }\end{array}$
\end{tabular}

\section{Optimal environment for shaping repertoires to tact private events}

\section{The learning environment is sensitive, but not too sensitive}

In an insensitive learning environment, opportunities for reinforcing appropriate tacts/ teaching new tacts are often missed. Similarly, a child may not tact experiences appropriately if they are not provided a label for that experience as it occurs. Even if a child has already acquired the relevant tact, in an optimal environment, someone would be available to both notice and reinforce the child's tact to ensure the repertoire does not undergo extinction.
A semi-sensitive environment, wherein tacting of emotions is only taught in response to extreme and infrequently occurring stimuli (e.g., only teaching "feeling sad" in response to marital separation), can severely limit a child's repertoire. In such an environment, the child may not learn to tact "sad" in everyday situations. Thus, the child's experience is partly blocked, limiting the extent to which they can predict the impact of certain stimuli on their experience.

An overly sensitive environment can inadvertently isolate a child by producing emotional responses that are not detected by people outside the environment. For example, a parent could notice a child's foot-tapping and provide the tact "you must 
be anxious" followed by reassurance. From this, the child could derive that tapping their foot leads to others understanding their anxiety and providing reassurance, meaning explicit tacts (e.g., verbalizing that they feel anxious) are somewhat redundant. However, outside the home environment, people are unlikely to respond to the child's tapping as the parent did, so the child may struggle to find people that will discriminate their emotional responses.

Therefore, the optimal environment for developing repertoires to tact private events is sensitive, but not too sensitive. When possible, caregivers should strive to be available and attentive in order to capitalize on opportunities to shape tacting. In addition, while caregivers should strive to provide appropriate tacts as experiences occur, they should also contextualize their responses and encourage explicit tacts that can be detected by other members of the community.

\section{Appropriate consequences are delivered and contacted}

If the learning environment fails to reinforce a child for tacting their private events, then, via punishment or extinction, the probability that the child will continue to tact these events in the environment or similar environments decreases. This is particularly important to consider with regard to invalidating environments. For example, consider a child telling their father that they are feeling upset because they came last in the race. If the father replies that the child isn't good at running anyway, then the father is failing to respond to the child's emotional tact. Over time, this pattern of ignoring the child's emotional tacts will decrease the probability that the child will continue tacting and may eventually extinguish the repertoire entirely. In a similar vein, if the learning environment punishes a child for accurately tacting their experience, then the child may avoid tacting in order to escape these aversive consequences. For example, consider a young boy who has accurately tacted that he is feeling upset. If he is met with invalidating responses such as "boys don't cry, toughen up" then he may begin avoiding this particular internal experience in order to escape invalidation. Therefore, it is important that we reinforce rather than punish children when they accurately tact their private events, responding to their emotional tacts rather than undermining or punishing them for having their experiences.

Avoidance is a natural response to aversive private events. While avoidance may be spurred on by punishment, it may also arise due to a child's discomfort with the aversive internal content (see Hayes, 2004 for more on experiential avoidance). For example, a child may say that they are "feeling fine" even when they are not in order to avoid fully connecting with the unwanted internal experience. However, as previously mentioned, contacting and labeling our experiences is important for flexible responding that is sensitive to changing contexts. If a child continuously does not connect with their internal experience, then they may fail to notice how particular contexts and stimuli impact them, causing problems in the long run. This disconnection from internal experiences and contingency insensitivity may also arise when children receive imprecise non-specific reinforcement for accurate tacting. For example, upon hearing their child say that they are feeling sad, a parent may bombard them with reinforcers (e.g., teddy bears, sweets, and cuddles) without appropriately responding to the child's emotional tact. This can impact the child's ability to discriminate the antecedent condition that led to the internal experience (see also Skinner's (1957) discussion of impure tacts). Therefore, it is important to encourage children to connect with their internal experiences when it is safe and useful for them to do so. Likewise, it is important to provide explicit reinforcers for accurate tacts while also encouraging children to explore antecedent conditions that precede private events.

\section{The child's experience dictates the child's experience}

Within the RFT account of rule-governed behavior, behavior under the control of apparent arbitrary social consequences (pliance) is distinguished from behavior under the control of apparent natural non-arbitrary consequences (tracking). If a child is in an environment where they are behaving solely to contact arbitrary social consequences (i.e., displaying generalized pliance), then these arbitrary consequences can begin to overwhelm natural consequences, promoting decreased sensitivity to 
shifting environmental contingencies (see Ruiz et al., 2019 for more on pliance). In addition to reducing the extent to which the child can discriminate their experience, generalized pliance is particularly problematic for accurate tacting of internal experiences because it typically forces a child to resort to people-pleasing. For example, consider a young girl who has accurately tacted that she is feeling angry. If her social community has failed to appropriately contextualize pliance (i.e., pliance has become generalized), then with social approval being her main reinforcer, she may reject this tact based on societal views around women expressing anger. In this example, a dominance of pliance in the girl's behavioral repertoire meant that rather than being guided by her experience, she behaved to please others. An optimal environment that facilitates the development of accurate repertoires for tacting private events should endeavor to contextualize pliance so that it does not become generalized. In addition, it is important to encourage children to be guided by their experiences rather than being guided only by social approval.

Related to this, the learning environment should not teach a child to be more sensitive to others' internal experiences than their own. While an awareness of others' internal experiences is important for processes such as empathy (discussed further below), ideally a child would not be taught to override or disregard their internal experience in favor of others'. For example, consider a child that is having fun at a playschool meet-up. Upon noticing that their parent is fed up, the child says that they are fed up and want to go home (i.e., the child discerns their parent's experience and adopts it as their own). In this example, the child's learning history was such that the parent had differentially reinforced the child's tacts based on how consistent the child's experience was with the parent's experience. The child learned that accurately tacting their experience would not lead to accessing reinforcement unless their experience was consistent with their parent's. As such, rather than attending to their private events, the child learned to discriminate their parent's needs and wants and tact consistent with those experiences.

Deliberate distortion of a child's internal experience may also occur if the learning environ- ment intentionally mislabels the experience. For example, consider a parent telling their child "you are not upset, I haven't upset you" when in fact the parent has upset the child. Forcing incorrect labels is detrimental to the development of repertoires for accurately tacting private events. In this example, the child may begin to discount the physical sensations in their body that indicate that they are feeling upset, making it harder for the child to both discriminate when they are feeling this way and to identify the contributing antecedents.

When teaching children to tact their private events, it is imperative that the child's experience dictates the child's experience (i.e., a child should not be taught to disregard/override their experience nor adopt others' experiences as their own). Learning environments can guide children in exploring their internal experiences but should not offer reinforcement based solely on consistency with societal norms or our own experiences. The overarching goal should be to sensitize a child to their private events, offering rather than prescribing labels.

\section{Facilitate rich discussion of private events and translate for the broader context} If a child is in an environment where emotions are not discussed, then they are unlikely to acquire an emotional vocabulary conducive to appropriately tacting their experiences. An absence of emotional talk means children are not provided with opportunities to experiment with labels for their private events nor receiving reinforcement for tacting. In the long run, this can impact the extent to which a child can discriminate their internal experience.

In a similar vein, if a child is in an environment with limited discussions of emotion, then the child is likely to develop a limited repertoire for tacting. For example, consider a learning environment that only provides a child with the label 'sad' to describe experiences of sadness, frustration, and disappointment. In this example, the child's repertoire for tacting these private events is limited to 'sad' and thus the child will likely struggle to discriminate sadness from frustration from disappointment. In this way, the child's ability to impact their environment is restricted to 'sad' behavior, with other forms of responding remaining out of reach. Therefore, rec- 
ognizing the importance of variability, caregivers should facilitate regular discussion of a range of private events, encouraging children to safely explore their internal experiences with curiosity while simultaneously providing rich and varied labels for those experiences.

Related to this is the importance of ensuring tacts function across contexts. For example, consider a child that uses the label 'fizzy' to describe their experience of excitement. In the home environment, this label is understood by caregivers and responded to appropriately. However, outside the home, 'fizzy' is ambiguous and does not consistently evoke responses from others. While helping a child to create their own labels for experiences is undoubtedly useful, it is important to contextualize that these tacts will elicit desired responses in some contexts and not others. Therefore, it can be helpful to also provide children with widely used labels that align with self-generated labels, facilitating effective discussions of internal experiences across contexts.

\section{Research on tacting internal experiences}

An exhaustive overview of empirical work examining tacting is beyond the scope of the present paper (for reviews, see Raaymakers et al., 2019; Tincani et al., 2020 for reviews). Instead, we will provide a brief overview of key articles on tacting private events that inform the previously discussed features of an optimal environment for shaping accurate tacting.

In terms of translational research on tacting private events, via an experimental analog study in a sample of undergraduate students, Stocco et al. (2014) examined conditions that influenced the accuracy reporting of private events. In this study, symbols visible only to participants were considered analogous to private events, with report accuracy being defined as a predetermined syllable-symbol relation. Participants were most accurate in their reporting when consequences were delivered based on public accompaniments that correlated strongly with the given private event (i.e., good predictors of the given private event). Furthermore, consistency in reinforcement across audience members (i.e., the verbal community) was conducive to more accurate reporting. The latter of these findings highlights the importance of translating any self-generated labels for the broader context to increase the probability that the child will receive consistent reinforcement for accurate tacting. As noted by Darrow and Follette (2014a), tacting is of particular importance with regard to alexithymia. See Darrow and Follette (2014a) for a discussion of alexithymia research in the context of its implications for optimal environments to shape accurate tacting.

A paucity of published empirical research has examined means of teaching accurate tacting of internal experiences. In a sample of three 5-year-old males with autism spectrum disorder, via a multicomponent intervention (discrete trial instruction, prompt, error correction, and reinforcement), McHugh et al. (2011) sought to teach tacting of others' situation-based emotions (i.e., happiness, sadness, anger, and fear) using videos. Findings revealed that participants learned to accurately tact the four emotions, further demonstrating generalization with novel stimuli in the presence of a novel individual in a novel setting with accuracy maintained 15 days post-training. Similarly, in a sample of three males (two five-year-olds, one ten-year-old) with diagnoses of autism, via PEAK-DT (Promoting the Emergence of Advanced Knowledge Relational Training System: Direct Training Module) procedures and public accompaniment, Belisle et al. (2020) taught children to tact others' private events (tired, sad, hurt, and mad). Findings revealed that children learned to accurately tact the emotions, with fast rates of acquisition observed. These studies highlight the importance of a learning environment that is both sensitive and delivers consequences when shaping tacting.

Highlighting the importance of facilitating discussions of private events, Conallen and Reed (2017) found that providing language with which to talk about private events enabled children to better initiate conversations about their experiences. More specifically, in a sample of children (eight males, two females) aged 5 to 9 years $(M=$ 6.7 years), via a picture symbol system, Conallen and Reed (2017) found that, following teaching, children both initiated conversations about their experiences (i.e., selected the 'talk' symbol) and demonstrated generalization of this behavior to 
novel situations. Via similar procedures, Conallen and Reed (2016) taught a sample of children (eight males, two females) aged 6 to 9 years $(M=$ 7.2 years) to match tacts to illustrated scenarios. Findings revealed that children learned to accurately tact the taught emotions in others, with these skills generalizing to both novel situations and the child's own private events.

\section{Deictic relational responding}

From an RFT perspective, deictic relating is a type of relational responding developed through interactions that provide opportunities to talk about one's perspective in relation to the perspective of others (McHugh et al., 2019). Deictic relational frames span across three dimensions: interpersonal (I-YOU relations), spatial (HERE-THERE relations), and temporal (NOW-THEN relations). Acquisition of these frames involves learning that one's own behavior in the moment is always from the perspective of I-HERE-NOW and that this differs from others' perspectives. For example, when you ask a child about their behavior, they will always respond from the position of I-HERE-NOW to the question asked by YOU, THERE (where you are), and THEN (when you asked). Seeing and relating to a perspective other than our own is a learned behavior developed as a result of derived relational responding. While most other relational frames typically have formal, non-arbitrary properties in the environment, deictic relating is abstract. Simply put, deictic frames do not have physical counterparts in the environment.
Upon successfully developing the deictic frames of I-YOU, HERE-THERE, and NOW-THEN, these frames become an inherent property of most of our verbal interactions.

A growing body of research suggests that the deictic relational frames of I-YOU, HERE-THERE, and NOW-THEN underpin the capacity to take perspective of one's own and others' experiences (see Montoya-Rodríguez et al., 2017b for a review). Perspective-taking is central to many core aspects of human social and emotional development, including empathy (i.e., transformation of emotional functions via deictic frames; see Vilardaga, 2009 and Vilardaga et al., 2012), self-compassion, compassion for others, acceptance, and a transcendent sense of self (Hayes et al., 2012; Hooper et al., 2015; McHugh \& Stewart, 2012). Furthermore, perspective-taking is crucial for social communication (McHugh, 2015). Specifically, if an individual does not understand that their own wants, wishes, and needs are different from those of others, it will be extremely difficult to discriminate what they themselves want, need, and care about, making it difficult to effectively communicate what they require and desire. Therefore, it is important that the verbal community endeavor to shape and enhance repertoires for deictic relational responding when possible. Drawing on McHugh et al. (2019), we will now describe some features of a theoretically optimal environment for enhancing repertoires for deictic relational responding. See Table 2 for a summary of these features. Given their overlap with the previous sections on tacting, the upcoming sections will be brief.

Table 2. A summary of the features of a theoretically optimal environment for enhancing repertoires for deictic relational responding.

\begin{tabular}{ll}
\hline Feature & Summary \\
\hline $\begin{array}{l}\text { Provides frequent interaction } \\
\text { Provides multiple exemplars of } \\
\text { distinctions between self and } \\
\text { others }\end{array}$ & $\begin{array}{l}\text { The learning environment provides multiple exemplars of deictic relations that span the three } \\
\text { dimensions (i.e., interpersonal, spatial, and temporal). }\end{array}$ \\
$\begin{array}{l}\text { Facilitates rich discussion of } \\
\text { helping a child to notice that in the moment they are always l-HERE-NOW whereas others } \\
\text { private events }\end{array}$ & $\begin{array}{l}\text { The learning environment sensitizes children to their internal experiences while also empha- } \\
\text { sizing that others can simultaneously have different experiences. }\end{array}$ \\
$\begin{array}{l}\text { Tailor to the individual when } \\
\text { drawing from training protocols }\end{array}$ & $\begin{array}{l}\text { Once the core elements and functions of evidence-based training protocols remain intact, } \\
\text { there is scope to tailor to the individual and their preferences in order to optimize outcomes. }\end{array}$
\end{tabular}




\section{Optimal environment for enhancing deictic relational responding}

\section{Facilitate frequent interaction}

Similar to learning environment sensitivity in the previous section, an optimal environment for enhancing deictic relational responding exposes a child to multiple exemplars of the involved relations. For example, asking questions such as "What did YOU do THEN?", "What are YOU doing NOW?", "What are YOU doing HERE?", "What will YOU do THERE?", "What did I do THEN?", "What am I doing NOW?" "What am I doing HERE?", "What will I do THERE?" facilitates the development of deictic relational responding by providing opportunities for the child to talk about perspectives in accordance with the three dimensions over which deictic relations span, namely interpersonal, spatial, and temporal. While the formal properties and physical environment will vary across all of the above questions, the invariant across contexts is always the relational properties of I versus YOU, HERE versus THERE, and NOW versus THEN. Drawing a child's attention to these relations enhances deictic relational responding, facilitating fluency and providing opportunities to notice distinctions between the self and others (see below).

\section{Provide multiple exemplars of distinctions between self and others}

Facilitating discussions involving deictic relations (i.e., asking "What are YOU doing NOW?") creates an opportunity to distinguish one's own perspective from that of others, shifting focus from the dimensions to distinctions (i.e., the versus). In an optimal learning environment, the verbal community would ask a child about themselves and further encourage the child to ask and answer questions involving deictic relational cues that span the three dimensions while also distinguishing self from other. Simply put, helping a child to notice that in the moment they are always I-HERE-NOW while others are THEY-THERE-THEN is central to healthy selfing and deictic relational responding.

When possible, caregivers should strive to initiate conversations that distinguish a child's self from that of others. This may be done in accordance with one or more of the dimensions simultaneously. For example, interpersonal; "I'm different from you", spatial; "Do you like it here at the park?", and temporal; "You finished your coloring really quickly!". An example combining dimensions could involve inviting a child to talk about their weekend versus a best friend's weekend; "What did Juwayriyah (THEY) do at home (THERE) over the weekend (THEN)? ... and what did you (SELF) do at home (HERE) over the weekend (THEN)?". An important common property across all of the questions we ask involving deictic cues is that we are looking for responses from the child's own perspective (i.e., I-HERE-NOW). When the child responds to questions involving deictic cues they are always responding from the perspective of their own behavior. This perspective-taking repertoire is critical to the development of a selfing repertoire.

\section{Facilitate rich discussion of private events}

Similar to the optimal environment for developing accurate repertoires for tacting, the learning environment should facilitate rich discussion of private events when enhancing deictic responding. Once a child can accurately tact their internal experiences, it is important that they also fluently understand that others have private events that differ from theirs. For example, consider a child that is feeling energized and excited at a social gathering while their parent is feeling anxious. In this example, if the child is unable to distinguish between their experiences and their parent's experiences (i.e., I-YOU), then the child may struggle to discriminate between energized and feeling anxious. As with training tacting, it is important to sensitize a child to their experience while also emphasizing that others can simultaneously have different experiences. This facilitates discrimination of private events, allowing for more accurate prediction of behavior both by ourselves and others.

\section{Tailor to the individual when drawing from existing training protocols}

Empirical work on deictic relations and perspectivetaking outlines best practice and provides evidencebased guidelines for training and enhancing deictic 
relational responding. Once the core elements and functions of these protocols remain intact, there is scope to tailor to the individual and their preferences. For example, rather than pulling exact stimuli from the McHugh et al. (2004) training protocol, "I have a red brick and you have a green brick. Which brick do I have? Which brick do YOU have?" (p.121), the verbal community can opt to use stimuli that are more relevant, interesting, and meaningful to the individual that they are working with (e.g., "I'm playing Among Us, you're using TikTok. What am I doing? What are you doing?")

Given that a brief overview of the literature on deictic relational responding will be presented in the next section, we will conclude this section by describing the core elements of these training protocols that should be maintained regardless of adaptations in line with what the evidence base shows to be best practice. Firstly, it is important to ensure that the necessary prerequisite skills are in place. Specifically, for this type of training to be effective, repertoires of joint attention, social referencing, tacting, relations of coordination, relations of distinction, and the ability to respond to 'what' questions such as "What is this object?" must be in place. Secondly, when initiating the training session, it is important to clarify and maintain consistency in the use of 'I' and 'YOU' (i.e., specify who each refers to). For example, "I, the Ph.D. student, am procrastinating. You, the reader, are being productive.." Actual names may be inserted here in place of roles. Consider your training context and make a decision in line with what works best for that context. Once specified, it is important from then onwards that the perspective is kept constant. Thirdly, when compiling the training sequences, trials should proceed from simple to more complex. In terms of dimensions, interpersonal (I-YOU) should be trained before spatial relations (HERETHERE) which should be trained before temporal relations (NOW-THEN).

In terms of delivering the training, physical prompts may be incorporated and faded out to aid learning. This could involve using actual objects (e.g., opening Among Us on your phone and opening TikTok on the child's device) or employing storybook formats (e.g., "Belle is here in the woods, you are there on the floor. If here was there and there was here. Where is Belle? Where are you?", as in Davlin et al., 2011, p.428). Outside the training format, tasks may also be performed throughout the day using whatever is currently happening. For example, "I am HERE writing a paper and YOU are THERE having a cup of tea. If I was you, what would I have?"

In terms of mastery criteria, evidence suggests that six consecutively correct responses to tasks should be given without additional prompts before moving to the next level of complexity or relation type (McHugh et al., 2019). As with all behavioral interventions, it is important to ensure sure that acquired skills generalize. Generalization to novel sets should be tested before moving on to more complex tasks and/or new relation types.

\section{Research on deictic relational responding}

An exhaustive overview of empirical work examining deictic relational responding is beyond the scope of the present paper (see Montoya-Rodríguez et al., 2017b for a review). Instead, we will provide a brief overview of key articles on training deictic relational responding that inform the previously discussed features of an optimal environment for enhancing deictic responding.

In their seminal work, across three studies with children and adults, McHugh et al. (2004) demonstrated that deictic relations follow a predictable developmental trend from early childhood to middle childhood, with deictic relational responding almost fully developed by adulthood in typically developing populations. McHugh et al. (2004) employed a deictic relational task (commonly referred to as the Barnes-Holmes protocol; see BarnesHolmes et al., 2004 for more) that assessed deictic ability using trials that required participants to take the perspectives interpersonally, spatially, and temporally. The lowest complexity deictic relation is a simple relation and involves identifying the perspective (e.g., "If I have a yellow brick and YOU have a blue brick: which brick do I have? Which brick do YOU have?"). The next level of complexity is a reversed relation, which involves reversing the perspectives (e.g., "If I have a yellow brick and 
you have a blue brick, and if I was you and you were me: which brick would I have? Which brick would you have?"), and finally, double-reversed relations, where the perspective is reversed twice (e.g., "I am sitting here on the blue chair and you are sitting there on the black chair. If I was you and you were me, and if here was there and there was here: where would you be sitting? Where would I be sitting?"). McHugh et al. (2004) found that the frequency of task errors decreased with age, with adult participants producing the least number of errors. Findings further revealed that for most participants, most errors were made on higher complexity trials (i.e., double-reversed relations).

The Barnes-Holmes protocol has been adapted and employed in a variety of contexts to establish and enhance deictic relational responding. Specifically, in samples of typically developing children, Davlin et al. (2011), Heagle and Rehfeldt (2006), and Weil et al. (2011) observed improvements in deictic responding following training. However, while participants tended to easily demonstrate stimulus generalization, response generalization required additional training (see Heagle and Rehfeldt, 2006). The Barnes-Holmes protocol has also beneficially impacted deictic relational responding among individuals diagnosed with schizophrenia (O’Neill \& Weil, 2014), an adult male with Down syndrome (Montoya-Rodríguez et al., 2017a), and children with autism (e.g., Jackson et al., 2014; Rehfeldt et al., 2007). In typically developing adults, rehearsing deictic relations has been shown to reduce the fundamental attribution error (Hooper et al., 2015) and deictic ability is significantly positively correlated with empathic concern (Vilardaga et al., 2012).

\section{Conclusion}

Tacting and deictic relational responding are fundamental to a healthy selfing repertoire. The present paper highlighted ways that the verbal community could endeavor to create environments that establish and enhance these processes. Specifically, in terms of tacting, it is important to consider the sensitivity of the learning environment, consequence availability, the individual's experience, and to fa- cilitate rich discussions of private events. In terms of deictic relational responding, it is important to provide frequent interactions that contain multiple exemplars of distinctions between self and others in addition to rich discussions of private events while also tailoring to the individual when drawing from training protocols. Once these two selfing processes are established, the individual can begin to acquire additional, more complex selfing repertoires, secure with a foundation for healthy selfing.

\section{References}

Barnes-Holmes, D., Barnes-Holmes, Y., \& Cullinan, V. (2000). Relational frame theory and Skinner's Verbal Behavior: A possible synthesis. The Behavior Analyst, 23(1), 69-84. https://doi. org/10.1007/BF03392000

Barnes-Holmes, Y., McHugh, L., \& Barnes-Holmes, D. (2004). Perspective-taking and theory of mind: A relational frame account. The Behavior Analyst Today, 5(1), 15-25. http://dx.doi. org/10.1037/h0100133

Belisle, J., Dixon, M. R., Alholai, A., Ellenberger, L., Stanley, C., \& Galliford, M. (2020). Teaching children with autism to tact the private events of others. Behavior Analysis in Practice, 13(1), 169-173. https://doi.org/10.1007/s40617-01900334-9

Conallen, K., \& Reed, P. (2016). A teaching procedure to help children with autistic spectrum disorder to label emotions. Research in Autism Spectrum Disorders, 23, 63-72. https://doi. org/10.1016/j.rasd.2015.11.006

Conallen, K., \& Reed, P. (2017). Children with autism spectrum disorder: Teaching conversation involving feelings about events. Journal of Intellectual Disability Research, 61(3), 279-291. https://doi.org/10.1111/jir.12339

Darrow, S. M., \& Follette, W. C. (2014a). A behavior analytic interpretation of alexithymia. Journal of Contextual Behavioral Science, 3(2), 98-108. https://doi.org/10.1016/j.jcbs.2014.03.002

Darrow, S. M., \& Follette, W. C. (2014b). Where's the beef?: Reply to Kanter, Holman, and Wilson. Journal of Contextual Behavioral Science, 3(4), 265-268. https://doi.org/10.1016/j. 
jcbs.2014.08.007

Davlin, N. L., Rehfeldt, R. A., \& Lovett, S. (2011). A relational frame theory approach to understanding perspective-taking using children's stories in typically developing children. European Journal of Behavior Analysis, 12(2), 403-430. https://doi.org/10.1080/15021149.20 11.11434392

Hayes, S. C. (2004). Acceptance and commitment therapy, relational frame theory, and the third wave of behavioral and cognitive therapies. Behavior Therapy, 35(4), 639-665. https://doi. org/10.1016/S0005-7894(04)80013-3

Hayes, S. C., Barnes-Holmes, D., \& Roche, B. (Eds.). (2001). Relational frame theory: A post-Skinnerian account of human language and cognition. Plenum Publishers.

Hayes, S. C., Strosahl, K. D., \& Wilson, K. G. (2012). Acceptance and commitment therapy: The process and practice of mindful change (2nd ed.). Guildford Press.

Heagle, A. I., \& Rehfeldt, R. A. (2006). Teaching perspective-taking skills to typically developing children through derived relational responding. Journal of Early and Intensive Behavior Intervention, 3(1), 1-34. http://dx.doi. org/10.1037/h0100321

Hooper, N., Erdogan, A., Keen, G., Lawton, K., \& McHugh, L. (2015). Perspective taking reduces the fundamental attribution error. Journal of Contextual Behavioral Science, 4(2), 69-72. https://doi.org/10.1016/j.jcbs.2015.02.002

Jackson, M. L., Mendoza, D. R., \& Adams, A. N. (2014). Teaching a deictic relational repertoire to children with autism. The Psychological Record, 64(4), 791-802. https://doi.org/10.1007/ s40732-014-0078-Z

Kanter, J. W., Holman, G., \& Wilson, K. G. (2014). Where is the love? Contextual behavioral science and behavior analysis. Journal of Contextual Behavioral Science, 3(2), 69-73. https://doi.org/10.1016/j.jcbs.2014.02.001

McHugh, L. (2015). A contextual behavioural science approach to the self and perspective taking. Current Opinion in Psychology, 2, 6-10. https://doi.org/10.1016/j.copsyc.2014.12.030

McHugh, L., Barnes-Holmes, Y., \& Barnes-Holmes, D. (2004). Perspective-taking as relational responding: A developmental profile. The Psychological Record, 54(1), 115-144. https:// doi.org/10.1007/BF03395465

McHugh, L., Bobarnac, A., \& Reed, P. (2011). Brief report: Teaching situation-based emotions to children with autistic spectrum disorder. Journal of Autism and Developmental Disorders, 41(10), 1423-1428. https://doi.org/10.1007/ s10803-010-1152-2

McHugh, L., \& Stewart, I. (2012). The self and perspective taking: Contributions and applications from modern behavioral science. New Harbinger Publications.

McHugh, L., Stewart, I., \& Almada, P. (2019). A contextual behavioral guide to the self: Theory and practice. New Harbinger.

Montoya-Rodríguez, M. M., McHugh, L., \& Molina, F. J. (2017a). Teaching perspectivetaking skills to an adult with Down syndrome: A case study. Journal of Contextual Behavioral Science, 6(3), 293-297. https://doi.org/10.1016/j. jcbs.2017.04.012

Montoya-Rodríguez, M. M., Molina, F. J., \& McHugh, L. (2017b). A review of relational frame theory research into deictic relational responding. The Psychological Record, 67(4), 569-579. https://doi.org/10.1007/s40732-0160216-x

O’Neill, J., \& Weil, T. M. (2014). Training deictic relational responding in people diagnosed with schizophrenia. The Psychological Record, 64(2), 301-310. https://doi.org/10.1007/s40732-0140005-3

Pierce, B. G., \& Levin, M. E. (2019). Preliminary validation and reliability assessment of a 10item Tacting of Function Scale. Journal of Contextual Behavioral Science, 12, 322-328. https://doi.org/10.1016/j.jcbs.2019.01.002

Raaymakers, C., Garcia, Y., Cunningham, K., Krank, L., \& Nemer-Kaiser, L. (2019). A systematic review of derived verbal behavior research. Journal of Contextual Behavioral Science, 12, 128-148. https://doi.org/10.1016/j. jcbs.2019.02.006

Rehfeldt, R. A., Dillen, J. E., Ziomek, M. M., \& Kowalchuk, R. K. (2007). Assessing relational learning deficits in perspective-taking in children with high-functioning autism spectrum 
disorder. The Psychological Record, 57(1), 23-47. https://doi.org/10.1007/BF03395563

Ruiz, F. J., Suárez-Falcón, J. C., Barbero-Rubio, A., \& Flórez, C. L. (2019). Development and initial validation of the Generalized Pliance Questionnaire. Journal of Contextual Behavioral Science, 12, 189-198. https://doi.org/10.1016/j. jcbs.2018.03.003

Skinner, B. F. (1957). Verbal behavior. B.F. Skinner Foundation.

Stocco, C. S., Thompson, R. H., \& Hart, J. M. (2014). Teaching tacting of private events based on public accompaniments: Effects of contingencies, audience control, and stimulus complexity. The Analysis of Verbal Behavior, 30(1), 1-19. https://dx.doi.org/10.1007\%2Fs40616014-0006-y

Tincani, M., Miller, J., Lorah, E. R., \& Nepo, K. (2020). Systematic review of verbal operants in speech generating device research from Skinner's analysis of verbal behavior. Perspectives on Behavior Science, 43, 387-413. https://doi.org/10.1007/s40614-020-00243-1

Vilardaga, R. (2009). A relational frame theory account of empathy. International Journal of Behavioral Consultation and Therapy, 5(2), 178184. http://dx.doi.org/10.1037/h0100879

Vilardaga, R., Estévez, A., Levin, M. E., \& Hayes, S. C. (2012). Deictic relational responding, empathy, and experiential avoidance as predictors of social anhedonia: Further contributions from relational frame theory. The Psychological Record, 62(3), 409-432. https://doi.org/10.1007/ BF03395811

Weil, T. M., Hayes, S. C., \& Capurro, P. (2011). Establishing a deictic relational repertoire in young children. The Psychological Record, 61(3), 371-390. https://doi.org/10.1007/BF03395767

\section{Informações do Artigo}

Histórico do artigo:

Recebido em: 30/11/2020

Primeira decisão editorial: 05/04/2021

Aceito em: 05/05/2021

Editor: William F. Perez 